\title{
Radiação, fotossíntese, rendimento e qualidade de frutos em macieiras 'Royal Gala' cobertas com telas antigranizo
}

\author{
Cassandro Vidal Talamini do Amarante ${ }^{(1)}$, Cristiano André Steffens ${ }^{(1)}$, Clenilso Sehnen Mota ${ }^{(1)}$ \\ e Henrique Pessoa dos Santos ${ }^{(2)}$
}

\begin{abstract}
(1)Universidade do Estado de Santa Catarina, Centro de Ciências Agroveterinárias, Av. Luiz de Camões, 2090, Caixa Postal 281, CEP 88520-000 Lages, SC. E-mail: amarante@cav.udesc.br, steffens@cav.udesc.br, clenilso@yahoo.com.br (2)Embrapa Uva e Vinho, Rua Livramento 515, Caixa Postal 130, CEP 95700-000 Bento Gonçalves, RS. E-mail: henrique@cnpuv.embrapa.br
\end{abstract}

\begin{abstract}
Resumo - $\mathrm{O}$ objetivo deste trabalho foi avaliar a intensidade e a qualidade da radiação solar disponibilizada às plantas e os seus impactos sobre a fotossíntese, rendimento e qualidade dos frutos, em macieiras 'Royal Gala', cobertas ou não com telas antigranizo nas cores branca e preta. A tela preta provocou redução maior na densidade de fluxo de fótons fotossinteticamente ativos acima do dossel das plantas (24,8\%), em comparação à tela branca $(21,2 \%)$. O interior do dossel das plantas sob tela preta recebeu menores valores de radiação ultravioleta, azul, verde, vermelho e vermelho distante, bem como da relação vermelho:vermelho distante, em relação às plantas descobertas. Estas alterações na quantidade e qualidade da luz sob tela preta aumentaram o teor de clorofila total e a área específica nas folhas, e reduziram a taxa fotossintética potencial, o peso de frutos por $\mathrm{cm}^{2}$ de seção transversal de tronco e a coloração vermelha dos frutos. As telas antigranizo branca e preta reduziram a incidência de queimadura de sol, porém não tiveram efeito sobre a severidade de "russeting" e sobre o número de sementes por fruto.
\end{abstract}

Termos para indexação: Malus domestica, sombreamento, intensidade de luz, qualidade da luz, cor do fruto, queimadura por sol.

\section{Radiation, photosynthesis, yield, and fruit quality of 'Royal Gala' apples under hail protection nets}

\begin{abstract}
The objective of this work was to assess the amount and quality of the light supplied to plants, and the resulting impacts on photosynthesis, yield, and fruit quality of 'Royal Gala' apple trees uncovered or covered with white and black hail protection nets. The black net caused a higher reduction $(24.8 \%)$ of photosynthetic photon flux density, accumulated over the plant canopy during the day, than the white net (21.2\%). The canopy internal portion of plants covered by black net received lower levels of ultraviolet, blue, green, red, and far red radiation, and light with a lower red:far red ratio, in comparison to uncovered plants; these ligth changes increased chlorophyll content and specific area of the leaves, and reduced the potential photosynthesis, the weight of fruits per $\mathrm{cm}^{2}$ of trunk cross section area, and the share of blush area in the fruit. White and black hail protection nets reduced the incidence of sunburn, but had no effect on russeting severity and number of seeds per fruit.

Index terms: Malus domestica, shading, light intensity, light quality, fruit skin color, sunburn.
\end{abstract}

\section{Introdução}

A ocorrência de granizo é um dos principais problemas enfrentados pelos produtores de maçã na Região Sul do Brasil. O cultivo da macieira (Malus domestica Borkh) ocorre em regiões de altitude que propiciam condições climáticas adequadas para a produção e a qualidade dos frutos. Essas mesmas condições climáticas de altitude favorecem a ocorrência de granizo, com prejuízos significativos aos produtores (Yuri, 2003).
O granizo é formado na parte superior de nuvens do tipo cúmulo-nimbos, onde a temperatura é menor e favorece a transformação de gotículas de água em partículas de gelo com diâmetro médio de $1,5 \mathrm{a} 2 \mathrm{~cm}$, que pode variar de 0,5 a $20 \mathrm{~cm}$ (Martinez et al., 2001). A ocorrência de granizo tem maior freqüência na primavera, especialmente nos meses de outubro e novembro, e ocorre em conseqüência dos complexos convectivos de mesoescala, que são áreas de instabilidade que se formam no Paraguai e no Norte da Argentina, 
região do Chaco (Marcelino et al., 2004). Essas áreas de instabilidade se deslocam em direção ao Oceano Atlântico e promovem a formação de granizo nos principais municípios produtores de maçã de Santa Catarina (Fraiburgo e São Joaquim) e Rio Grande do Sul (Vacaria).

O granizo ocorre de forma localizada, não atinge grandes áreas, mas pode ocasionar significativa redução na qualidade e quantidade de frutos destinados à comercialização, assim como danos às arvores em formação e em produção, o que compromete as produções futuras (Leite et al., 2002). Isto tem levado à adoção, por parte dos produtores, de alternativas para a administração dos prejuízos, que incluem a utilização de foguetes antigranizo, geradores de solo, o seguro agrícola e a cobertura dos pomares com telas antigranizo (Yuri, 2003).

A cobertura das linhas de plantas com telas é considerada o método mais seguro de proteção contra o granizo (Poldervaart, 2006), e seu emprego tem aumentado, especialmente no Estado de Santa Catarina. Leite et al. (2002) estudaram o uso de tela de proteção na cultura da macieira, no Município de Fraiburgo, SC, e relataram, com base em dados de cinco anos, ausência total de danos de granizo nos frutos em plantas cobertas. Esses mesmos autores salientaram que as plantas descobertas apresentam perda média anual de $6,5 \%$ da produção, em conseqüência do dano de granizo aos frutos, podendo chegar, em anos de granizo intenso, a $45,9 \%$.

A implantação do sistema de telas antigranizo, em pomares, apresenta elevado custo referente a moirões, arames, telas e mão-de-obra, e é estimado entre R\$ 15 mil e R\$ 20 mil por hectare (Kreuz et al., 2002). A tela antigranizo é confeccionada com tramas finas, que proporciona maior resistência mecânica, capaz de suportar fortes chuvas de granizo, recebe tratamento de proteção contra radiação ultravioleta (UV) e sua durabilidade alcança cerca de 15 anos para a tela preta e 10 anos para a tela branca (Tassara \& Battaglia, 1992).

A tela antigranizo reduz a radiação solar incidente sobre as plantas, e pode por isso interferir na fotossíntese e na produção e na qualidade dos frutos. A intensidade desses efeitos está relacionada com o grau de sombreamento (dependente da coloração e da malha da tela), da combinação cultivar/portaenxerto, da densidade de plantio, do sistema de manejo e condução das plantas, e da região de produção (Gardner \& Fletcher, 1990; Tassara \& Battaglia, 1992; Chen et al., 1997; Widmer, 2001; Leite et al., 2002;
Middleton \& McWaters, 2002; Stampar et al., 2002; Warnier, 2004).

Este trabalho foi conduzido em pomar de macieira 'Royal Gala', com a finalidade de estudar os efeitos do emprego de telas antigranizo, nas cores branca e preta, sobre a intensidade e qualidade da radiação solar disponibilizada às plantas, e os seus impactos sobre a fotossíntese, rendimento e qualidade dos frutos.

\section{Material e Métodos}

O experimento foi conduzido em pomar comercial no Município de Vacaria, RS, a 930 m de altitude, 28²2'52,1"S e 50 50'46,3"W, durante três ciclos produtivos (2003/2004 a 2005/2006). Foram utilizadas macieiras 'Royal Gala' de oito a dez anos de idade, sobre porta-enxerto M9, conduzidas com líder central, em sistema de alta densidade, com espaçamento de $3,5 \times 0,8 \mathrm{~m}$.

O delineamento experimental foi em blocos ao acaso, com cinco repetições, em que cada planta representou uma repetição. Os tratamentos consistiram do controle (plantas não cobertas com tela antigranizo) e da cobertura das plantas com telas antigranizo (Sombrite), nas cores branca e preta, com malha de $4 \times 7 \mathrm{~mm}$. As plantas dos tratamentos com tela permaneceram cobertas durante todo o ciclo (dormência e crescimento vegetativo). As telas branca e preta foram montadas ao longo da linha de plantio, em outubro de 1999, seguindo a orientação Norte-Sul, no formato de cobertura de duas águas, com distância entre filas de $20-30 \mathrm{~cm}$, para permitir a queda de pedras de granizo entre as filas de plantas. Foram cobertas nove linhas de plantas, ao longo de $140 \mathrm{~m}$, com cada uma das telas utilizadas (branca e preta). Foram utilizadas cinco plantas da linha central, na porção mediana da extensão total coberta com as telas, para as avaliações de fotossíntese, rendimento e qualidade de frutos, além de cinco plantas na área descoberta, distante cinco linhas da área coberta.

Acima do dossel das plantas, nas áreas cobertas ou não com telas antigranizo, a densidade de fluxo de fótons fotossinteticamente ativos (DFFFA, $\lambda=400-700 \mathrm{~nm}$ ) foi determinada com um sensor quântico plano marca Li-Cor, modelo LI-190, conectado a um datalogger modelo LI-1400, no período de 5 às $20 \mathrm{~h}$, para medição de irradiância, corrigida para o co-seno do ângulo de incidência da luz, até valores de $80^{\circ}$.

A irradiância espectral (IE) foi determinada com um espectrorradiômetro portátil marca Li-Cor, modelo LI-1800, 
na altura do terço médio do dossel das plantas, nas regiões entre as linhas e na linha de plantas (no interior do dossel), bem como em área aberta, no nível acima do dossel das plantas, fora do pomar. Este espectrorradiômetro possui um receptor para o monitoramento da taxa de fluência, mede a luz onidirecional, ou seja, radiação incidente de diversas direções, nos diferentes comprimentos de onda na faixa de 300-1.100 nm, em um plano hemisférico $\left(180^{\circ}\right)$. As medições de IE foram realizadas próximo ao meio-dia. A partir dos dados de IE, foram quantificados os valores médios de energia luminosa, nas faixas do espectro correspondentes à radiação ultravioleta (UV, 300-400 nm), azul (400-450 nm), verde $(450-530 \mathrm{~nm})$, vermelho $(600-700 \mathrm{~nm})$, vermelho distante $(700-750 \mathrm{~nm})$ e total $(300-750 \mathrm{~nm})$ (Awad et al., 2001). Os valores foram quantificados em porcentagem, em relação à IE na área aberta, fora do pomar, acima do dossel. A irradiância espectral, nos comprimentos de onda de 645 e $735 \mathrm{~nm}$, foi utilizada para o cálculo da relação vermelho:vermelho distante (V:VD).

A curva de taxa de assimilação líquida de $\mathrm{CO}_{2}$ $\left(\mathrm{A}, \mu \mathrm{mol} \mathrm{CO} \mathrm{CO}_{2} \mathrm{~m}^{-2} \mathrm{~s}^{-1}\right)$, em resposta à DFFFA, em valores de $0,90,250,600$ e $1.000 \mu \mathrm{mol}$ de fótons $\mathrm{m}^{-2} \mathrm{~s}^{-1}$, foi determinada com o analisador de gás por infravermelho (IRGA) portátil, marca Li-Cor, modelo LI-6400, que foi operado em sistema aberto, equipado com fonte de luz modelo LI-6400-02B. As avaliações foram efetuadas em uma folha por repetição, próximo ao meio-dia, tendo-se utilizado sempre a folha do terço médio das plantas, não sombreada por outras folhas e oposta aos frutos.

Na curva de resposta de A, em função da DFFFA, foi ajustada a função hiperbólica $A=a+\left[\left(A_{\max } \times\right.\right.$ DFFFA $) /(b+$ DFFFA $)]$, em que $A_{\max }$ é a taxa máxima de fotossíntese e a e b são coeficientes de ajuste da equação. Esta curva de resposta permite calcular a respiração no escuro (coeficiente a da equação), o ponto de compensação de luz $(\Gamma$, correspondente ao valor de DFFFA em que A é igual a zero) e estimar a eficiência quântica aparente $\left(\Phi_{\mathrm{a}}, \mu \mathrm{mol} \mathrm{CO} \mathrm{CO}_{2}\right.$ por $\mu \mathrm{mol}$ de fótons). A variável $\Phi_{\mathrm{a}}$ foi estimada pelo ajuste de uma equação linear, na faixa em que a variação de $\mathrm{A}$ em função da DFFFA era linear, isto é, $\mathrm{A}=\mathrm{c}+\left(\Phi_{\mathrm{a}} \times\right.$ DFFFA $)$, em que c e $\Phi_{a}$ são coeficientes de ajuste. Na função hiperbólica, $\mathrm{A}_{\max }$ e b correspondem aos valores de $\mathrm{V}_{\max }$ e $\mathrm{K}_{\mathrm{m}}$ (constante de Michaelis-Menten) de ensaio enzimático. Portanto, esta função permite calcular a DFFFA correspondente à metade da $\mathrm{A}_{\max }$ (coeficiente $\mathrm{b}$ da equação, equivalente ao $\mathrm{K}_{\mathrm{m}}$ ), correspondente à eficiência de assimilação de $\mathrm{CO}_{2}$ com o incremento na DFFFA, o que reflete, assim, a $\Phi_{\mathrm{a}}$.

As avaliações de DFFFA, IE e A foram feitas em condição de céu completamente limpo, no dia 19/1/2006.

Por volta de 30 dias antes da colheita comercial dos frutos (24/1/2006), foram realizadas amostragens de 20 folhas por repetição, no terço médio de lançamentos do ano, para a avaliação de teor total de clorofila $\left(\mathrm{g} \mathrm{m}^{-2}\right)$, área foliar $\left(\mathrm{em} \mathrm{cm}^{2}\right.$, com um integrador de área foliar LI-COR modelo LI-3050A), matéria seca (em g, após secagem durante 72 horas a $65^{\circ} \mathrm{C}$ ) e área foliar específica $\left(\mathrm{cm}^{2} \mathrm{~g}^{-1}\right)$. A extração e a quantificação do teor total de clorofila foram feitos conforme Passos (1996).

Todos os frutos de cada planta na maturação comercial, provenientes das três safras de execução do trabalho, foram colhidos, contados e pesados, para a determinação do rendimento (número e peso de frutos por $\mathrm{cm}^{2}$ de seção transversal de tronco) e do peso médio de frutos ( $\mathrm{g}$ ). Foram selecionados 30 frutos de cada planta, com tamanho uniforme (calibre 120-135), os quais foram avaliados quanto à coloração, porcentagem de frutos com queimadura de sol, severidade de "russeting" $\left(\mathrm{cm}^{2}\right.$ fruto $\left.^{-1}\right)$ e número de sementes por fruto. A coloração foi avaliada em termos de superfície colorida do fruto (porcentagem de cor vermelha), por meio de análise subjetiva visual, e de valores de brilho (ou 'lightness', L) e ângulo hue $\left(\mathrm{h}^{\circ}\right)$, determinados com o auxílio de um colorímetro Minolta modelo CR 400, nos lados mais e menos expostos à luz, correspondentes aos lados com maior e menor intensidade de coloração vermelha, respectivamente.

Os dados foram submetidos às análises de regressão e de variância, e as médias de tratamentos foram comparadas pelo teste de Tukey, a 5\% de probabilidade.

\section{Resultados e Discussão}

Houve redução substancial na DFFFA, quantificada ao longo do dia, acima do dossel das plantas, nas áreas cobertas com telas, comparativamente à área descoberta (Figura $1 \mathrm{~A}$ ). Considerando-se o total acumulado ao longo do dia, a tela preta ocasionou maior redução na DFFFA $(24,8 \%)$ do que a tela branca $(21,2 \%)$, em relação à área descoberta (Figura 1 B). Widmer (2001) e Middleton \& McWaters (2002) também observaram maiores reduções na DFFFA, em pomares de macieiras sob telas antigranizo pretas do que sob telas brancas. 
O sombreamento ocasionado pelas telas antigranizo resultou em menores valores de respiração no escuro $\left(\mathrm{R}_{\mathrm{e}}\right)$, ponto de compensação de luz $(\Gamma)$ e taxa máxima de fotossíntese $\left(\mathrm{A}_{\max }\right)$ nas folhas, em resposta ao aumento na DFFFA, especialmente no tratamento com tela preta (Figura 2). A $\mathrm{R}_{\mathrm{e}}$ (coeficiente a da equação hiperbólica ajustada) foi de $0,65,0,58$ e $0,49 \mu \mathrm{mol}$ de $\mathrm{CO}_{2} \mathrm{~m}^{-2} \mathrm{~s}^{-1}$ nos tratamentos controle, tela branca e tela preta, respectivamente. Os valores de $\Gamma$ foram de 8,24, 7,21, e $5,47 \mu \mathrm{mol}$ de fótons $\mathrm{m}^{-2} \mathrm{~s}^{-1}$ nos tratamentos controle, tela branca e tela preta, respectivamente. Plantas descobertas e plantas cobertas com telas branca e preta apresentaram valores de $\mathrm{A}_{\max }$ correspondentes a 16,25, 13,69 e $12,10 \mu \mathrm{mol}$ de $\mathrm{CO}_{2} \mathrm{~m}^{-2} \mathrm{~s}^{-1}$, respectivamente. A eficiência quântica aparente foi similar entre os tratamentos, correspondente a valores de 0,0684, 0,0711 e 0,0673 $\mu \mathrm{mol}$ de $\mathrm{CO}_{2}$ por $\mu \mathrm{mol}$ de fótons nas plantas sem cobertura e

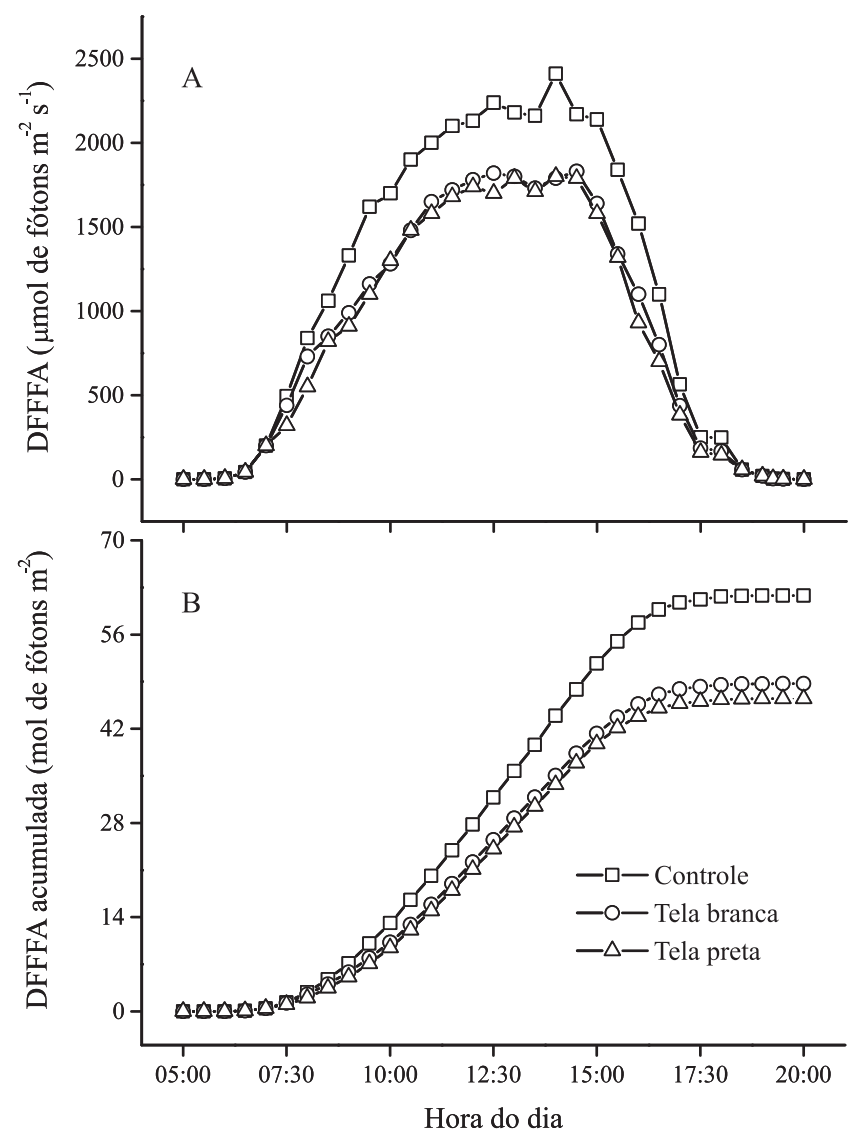

Figura 1. Densidade de fluxo de fótons fotossinteticamente ativos (DFFFA) incidente (A) e acumulada ao longo do dia (B), quantificada acima do dossel, em macieiras 'Royal Gala' descobertas (controle) ou cobertas com telas antigranizo nas cores branca e preta. naquelas cobertas com tela branca e tela preta, respectivamente. Os valores do coeficiente $b$ das equações hiperbólicas ajustadas (DFFFA correspondente à metade da $\mathrm{A}_{\max }$ ) (Figura 2) foram maiores nas plantas do tratamento controle $\left(197,2 \mu \mathrm{mol}\right.$ de fótons $\left.\mathrm{m}^{-2} \mathrm{~s}^{-1}\right)$ do que em plantas cobertas com telas branca $(163,1 \mu \mathrm{mol}$ de fótons $\left.\mathrm{m}^{-2} \mathrm{~s}^{-1}\right)$ e preta $\left(129,7 \mu \mathrm{mol}\right.$ de fótons $\left.\mathrm{m}^{-2} \mathrm{~s}^{-1}\right)$.

Esses resultados mostram que o sombreamento ocasionado pelas telas aumentou a eficiência fotossintética em baixos valores de DFFFA, caracterizado pelos menores valores de $\mathrm{R}_{\mathrm{e}}, \Gamma \mathrm{e}$ coeficiente $\mathrm{b}$ das equações hiperbólicas ajustadas, mas ocasionou menor $A_{\max }$. A redução da $R_{e}$, em folhas sombreadas, é uma estratégia importante para a redução do $\Gamma$, por aumentar a eficiência de captação e uso da pouca luz disponível em ambiente sombreado (Dussi et al., 2005). Isso ocasiona redução nos valores de $A_{\max }$, em plantas sombreadas pela tela, como resultado da maior limitação imposta pelas reações de carboxilação ao incremento na fotossíntese, em elevados valores de DFFFA, comparativamente às plantas descobertas (Lambers et al., 1998).

Plantas cobertas com tela antigranizo branca e preta apresentaram maiores valores de área foliar específica e teor de clorofila total, em relação às plantas descobertas, e as plantas cobertas com tela preta

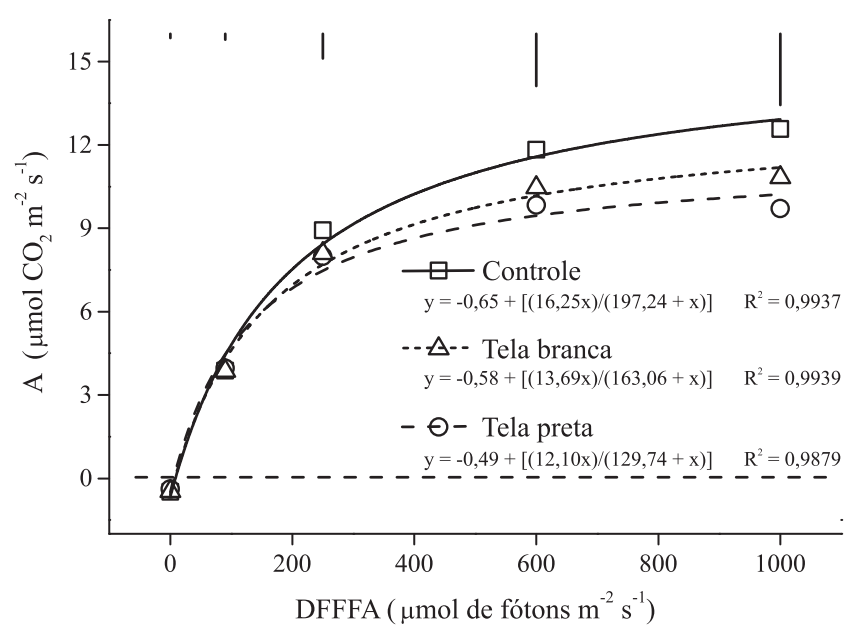

Figura 2. Taxa foliar de assimilação líquida de $\mathrm{CO}_{2}(\mathrm{~A})$, em resposta à densidade de fluxo de fótons fotossinteticamente ativos (DFFFA), em macieiras 'Royal Gala' descobertas (controle) ou cobertas com telas antigranizo nas cores branca e preta. Diferenças mínimas significativas entre tratamentos, para cada nível de DFFFA, indicadas no interior da figura (barras verticais), foram calculadas pelo teste de Tukey $(\mathrm{p}<0,05)$. 
apresentaram a maior área foliar específica (Tabela 1). Esta adaptação foliar ao sombreamento sob tela, em macieiras 'Royal Gala', também contribui para a maior eficiência fotossintética em condições da baixa DFFFA (Dussi et al., 2005).

Mesmo com as alterações verificadas na fotossíntese e no desenvolvimento foliar para adaptação à menor disponibilidade de luz em plantas sombreadas, não houve redução no número de frutos por $\mathrm{cm}^{2}$ de seção transversal de tronco (Tabela 1). No entanto, o peso de frutos por $\mathrm{cm}^{2}$ de seção transversal de tronco foi reduzido significativamente sob tela preta.

Nas áreas cobertas com tela branca e preta, houve, respectivamente, redução de aproximadamente 30 e $40 \%$ nas radiações UV, azul, verde e vermelho na entrelinha, em relação à área aberta. No interior do dossel, esta redução em relação à área aberta foi de $81 \%$ e $89 \%$, nas áreas cobertas com tela branca e preta, respectivamente (Tabela 2). A relação V:VD apresentou redução na entrelinha e no interior do dossel das plantas sob telas antigranizo, especialmente na tela preta (Tabela 2).

Os menores valores de radiação UV, azul, verde e vermelho, e da relação V:VD, no interior do dossel sob tela antigranizo preta (Tabela 2), resultaram em frutos com menor porcentagem de coloração vermelha (Tabela 3), o que confirma resultados obtidos por outros autores, sobre os efeitos da quantidade e qualidade da radiação na coloração de maçãs (Gardner \& Fletcher, 1990; Awad et al., 2001; Leite et al., 2002; Stampar et al., 2002). A síntese de antocianinas, na epiderme de maçãs, é controlada por uma fotorreação de alta energia, com máximo de ação entre 650 e $670 \mathrm{~nm}$, com uma faixa subsidiária entre 430 e $480 \mathrm{~nm}$ (Downs et al., 1965). Em pós-colheita, o tratamento de maçãs com luz branca mais luz UV-B (312 $\mathrm{nm})$ proporciona elevada síntese de antocianinas, com efeito aditivo do tratamento com luz vermelha e azul (Arakawa, 1988). A combinação de luz branca e UV promove a síntese de diferentes classes de flavonóides, entre eles as antocianinas

Tabela 1. Conteúdo de clorofila, área média e área específica das folhas, e rendimento e peso médio de frutos, em macieiras 'Royal Gala' descobertas (controle) ou cobertas com telas antigranizo nas cores branca e preta ${ }^{(1)}$.

\begin{tabular}{lcccccc}
\hline Tratamento & $\begin{array}{c}\text { Clorofila } \\
\text { foliar } \\
\left(\mathrm{g} \mathrm{m}^{-2}\right)\end{array}$ & $\begin{array}{c}\text { Área foliar } \\
\text { média } \\
\left(\mathrm{cm}^{2}\right)\end{array}$ & $\begin{array}{c}\text { Área foliar } \\
\text { específica } \\
\left(\mathrm{cm}^{2} \mathrm{~g}^{-1}\right)\end{array}$ & $\begin{array}{c}\text { No de frutos } \mathrm{cm}^{-2} \text { de seção } \\
\text { transversal de tronco }\end{array}$ & $\begin{array}{c}\text { Massa }(\mathrm{g}) \text { de frutos cm-2 de } \\
\text { seção transversal de tronco }\end{array}$ & $\begin{array}{c}\text { Peso médio } \\
\text { de frutos } \\
(\mathrm{g})\end{array}$ \\
\hline Controle & $207,93 \mathrm{~b}$ & $32,376 \mathrm{~b}$ & $114,00 \mathrm{c}$ & $5,08 \mathrm{a}$ & $683,07 \mathrm{a}$ & $136,24 \mathrm{a}$ \\
Tela branca & $233,47 \mathrm{a}$ & $33,214 \mathrm{ab}$ & $128,00 \mathrm{~b}$ & $5,04 \mathrm{a}$ & $672,65 \mathrm{ab}$ & $134,37 \mathrm{a}$ \\
Tela preta & $233,59 \mathrm{a}$ & $37,504 \mathrm{a}$ & $151,92 \mathrm{a}$ & $4,14 \mathrm{a}$ & $538,69 \mathrm{~b}$ & $133,03 \mathrm{a}$ \\
\hline $\mathrm{CV}(\%)$ & 6,18 & 11,42 & 14,03 & 18,71 & 18,18 & 5,55 \\
\hline
\end{tabular}

${ }^{(1)}$ Valores seguidos por letras iguais, nas colunas, não diferem entre si pelo teste de Tukey, a 5\% de probabilidade.

Tabela 2. Porcentagem da radiação incidente em relação à área aberta (fora do pomar), nas diferentes faixas do espectro, e relação vermelho:vermelho distante (V:VD), quantificados nas regiões da entrelinha e do interior do dossel, em macieiras 'Royal Gala' descobertas (controle) ou cobertas com telas antigranizo nas cores branca e preta ${ }^{(1)}$.

\begin{tabular}{llllccccc}
\hline Tratamento & Região do pomar & \multicolumn{4}{c}{ Nível de radiação incidente } & & \multicolumn{2}{c}{ Relação V:VD } \\
\cline { 3 - 8 } & & & UV & Azul & Verde & $\begin{array}{c}\text { Vermelho } \\
\text { (V) }\end{array}$ & $\begin{array}{c}\text { Vermelho } \\
\text { distante (VD) }\end{array}$ & $\begin{array}{c}\text { Radiação } \\
\text { total }\end{array}$ \\
\hline Controle & Entrelinha & $99,67 \mathrm{a}$ & $99,35 \mathrm{a}$ & $98,81 \mathrm{a}$ & $98,53 \mathrm{a}$ & $99,92 \mathrm{a}$ & $99,96 \mathrm{a}$ & $1,51 \mathrm{a}$ \\
& Interior do dossel & $27,06 \mathrm{~A}$ & $28,00 \mathrm{~A}$ & $28,77 \mathrm{~A}$ & $29,24 \mathrm{~A}$ & $42,27 \mathrm{~A}$ & $42,50 \mathrm{~A}$ & $0,98 \mathrm{~A}$ \\
\hline Tela branca & Entrelinha & $65,58 \mathrm{~b}$ & $65,15 \mathrm{~b}$ & $65,71 \mathrm{~b}$ & $67,21 \mathrm{~b}$ & $73,34 \mathrm{~b}$ & $72,07 \mathrm{~b}$ & $1,38 \mathrm{~b}$ \\
& Interior do dossel & $17,32 \mathrm{AB}$ & $18,70 \mathrm{AB}$ & $19,68 \mathrm{AB}$ & $21,28 \mathrm{AB}$ & $32,04 \mathrm{AB}$ & $31,47 \mathrm{AB}$ & $0,89 \mathrm{AB}$ \\
\hline Tela preta & Entrelinha & $60,23 \mathrm{~b}$ & $59,51 \mathrm{~b}$ & $59,23 \mathrm{~b}$ & $59,03 \mathrm{~b}$ & $62,31 \mathrm{~b}$ & $61,05 \mathrm{~b}$ & $1,43 \mathrm{~b}$ \\
& Interior do dossel & $10,38 \mathrm{~B}$ & $11,05 \mathrm{~B}$ & $11,85 \mathrm{~B}$ & $12,03 \mathrm{~B}$ & $20,34 \mathrm{~B}$ & $24,69 \mathrm{~B}$ & $0,79 \mathrm{~B}$ \\
\hline
\end{tabular}

(1)Valores seguidos por letras iguais nas colunas, minúsculas para a região da entrelinha e maiúsculas para a região do interior do dossel, não diferem entre si pelo teste de Tukey, a 5\% de probabilidade; comprimentos de onda: UV, 300-400 nm; azul, 400-450 nm; verde, 450-530 nm; vermelho, 600-700 nm; vermelho distante, 700-750 nm; radiação total, 300-750 nm. (2)Porcentagem em relação à área aberta, acima do dossel. 
(Reay \& Lancaster, 2001). A relação V:VD também afeta a coloração dos frutos. Segundo Awad et al. (2001), valores desta relação inferiores a 1, observados no interior do dossel de macieiras 'Jonagold', reduziram o conteúdo de cianidina 3-galactosídeo (antocianina), quercetina 3-glicosídeo e flavonóides totais, o que resultou em coloração vermelha deficiente nos frutos.

$\mathrm{O}$ sombreamento ocasionado pelas telas branca e preta aumentou os valores de $\mathrm{L}$ e $\mathrm{h}^{\circ}$ no lado sombreado, enquanto a tela preta também aumentou esses valores no lado exposto à luz (Tabela 3 ). $\mathrm{O}$ acúmulo de antocianinas ocasiona redução nos valores de $\mathrm{L}$ e $\mathrm{h}^{\circ}$ e reflete a mudança de cor verde para vermelha. Como resultado, o lado exposto à luz apresentou menores valores de $\mathrm{L}$ e $\mathrm{h}^{\mathrm{o}}$ do que o lado sombreado, em todos os tratamentos, como resultado do maior acúmulo de antocianina e maior intensidade de cor vermelha.

Houve menor incidência de queimadura de $\operatorname{sol}(\mathrm{p}<0,05)$, em frutos de plantas cobertas com telas antigranizo branca $(2,89 \%)$ e preta $(1,56 \%)$, do que em plantas descobertas $(5,56 \%)$ (valores médios de três safras). Isto confirma dados de outros autores e mostra que a redução na intensidade luminosa, em plantas sob tela, reduz a incidência de frutos com queimadura de sol, na cultura da macieira (Tassara \& Battaglia, 1992; Leite et al., 2002; Middleton \& McWaters, 2002; Stampar et al., 2002).

Os tratamentos não tiveram efeito significativo sobre a severidade de "russeting" (área de sintoma/fruto), que foi de $6,5,3 \mathrm{e} 4,1 \mathrm{~cm}^{2}$ fruto $^{-1}$, em plantas descobertas e em plantas cobertas com telas antigranizo branca e preta, respectivamente (valores médios de três safras). O emprego de telas pode aumentar a severidade de "russeting", devido à restrição no movimento de ar nesse ambiente, e ocasionar, assim, maior umidade relativa (Middleton \& McWaters, 2002), que está associada à

Tabela 3. Cor dos frutos em macieiras 'Royal Gala' descobertas (controle) ou cobertas com telas antigranizo nas cores branca e $\operatorname{preta}^{(1)}$.

\begin{tabular}{|c|c|c|c|c|c|}
\hline \multirow[t]{2}{*}{ Tratamento } & \multirow{2}{*}{$\begin{array}{c}\text { Cor } \\
\text { vermelha } \\
(\%)\end{array}$} & \multicolumn{2}{|c|}{ Lado sombreado } & \multicolumn{2}{|c|}{ Lado exposto à luz } \\
\hline & & $\mathrm{L}$ & $\mathrm{h}^{\mathrm{o}}$ & $\mathrm{L}$ & $\mathrm{h}^{\mathrm{o}}$ \\
\hline Controle & $74,08 \mathrm{a}$ & $69,77 b$ & $77,94 \mathrm{~b}$ & $49,40 \mathrm{~b}$ & $36,53 b$ \\
\hline Tela branca & 71,42ab & $73,50 \mathrm{a}$ & $88,90 \mathrm{a}$ & $50,50 \mathrm{~b}$ & $38,09 \mathrm{~b}$ \\
\hline Tela preta & $60,83 b$ & $72,96 \mathrm{a}$ & $91,48 \mathrm{a}$ & $53,32 \mathrm{a}$ & $48,48 \mathrm{a}$ \\
\hline $\mathrm{CV}(\%)$ & 12,27 & 8,69 & 21,83 & 13,41 & 31,16 \\
\hline
\end{tabular}

(1)Valores seguidos por letras iguais, nas colunas, não diferem entre si pelo teste de Tukey, a 5\% de probabilidade. manifestação do distúrbio em maçãs. No entanto, Leite et al. (2002) e Stampar et al. (2002) observaram menor severidade de "russeting", em plantas cobertas pela tela, em relação a plantas descobertas, como resultado da diminuição da radiação solar, que é um dos fatores que reduz a manifestação do distúrbio.

A tela antigranizo pode comprometer o processo de polinização entomófila das macieiras (Leite et al., 2002; Yuri, 2003) e, portanto, a frutificação efetiva e o rendimento de frutos. Entretanto, o número de sementes por fruto não diferiu entre plantas descobertas e plantas cobertas com telas (com valores médios em todos os tratamentos de 6,2 sementes por fruto), evidência de que a tela não interfere com a atividade polinizadora de abelhas. Portanto, a redução no rendimento de frutos, expressa em $\mathrm{g}$ por $\mathrm{cm}^{2}$ de seção transversal de tronco, em plantas cobertas com tela preta (Tabela 1), pode ser consequiência da redução no suprimento de luz, que reduz o acúmulo de reservas e pode comprometer a diferenciação de gemas reprodutivas e a frutificação efetiva (Chen et al., 1997; Middleton \& McWaters, 2002).

Os resultados obtidos mostram que a tela branca é mais indicada na proteção ao granizo em macieiras 'Royal Gala', apesar de sua menor durabilidade, já que permite maior intensidade e melhor qualidade de luz, necessários para a fotossíntese e o acúmulo de antocianinas na casca dos frutos, em comparação à tela preta. Todavia, mesmo com emprego de tela branca, cuidados especiais devem ser tomados quanto ao manejo e condução, especialmente no que diz respeito a podas, para permitir maior penetração de luz no dossel das plantas e assim aumentar a cor vermelha dos frutos, principalmente em regiões e safras agrícolas com condições climáticas desfavoráveis ao acúmulo de antocianinas nos frutos (Awad et al., 2001). Aliado a isto, o plantio de mutações de 'Gala' com maior coloração vermelha, como é o caso de 'Imperial Gala' e 'Galaxy', sobre porta-enxerto anão, pode tornar o emprego de tela antigranizo branca uma alternativa viável e de baixo impacto no comprometimento da qualidade dos frutos.

\section{Conclusões}

1. A cobertura de macieiras 'Royal Gala' com tela antigranizo preta ocasiona redução na densidade de fluxo de fótons fotossinteticamente ativos acumulada acima do dossel das plantas, bem como na radiação UV, azul, verde, vermelho e vermelho distante e na relação vermelho:vermelho distante no interior do dossel das plantas. 
2. A redução na intensidade e na qualidade da luz, ocasionada pela tela antigranizo preta, resulta em aumento no teor de clorofila total e na área específica nas folhas e redução na taxa fotossintética potencial, o que leva à redução no rendimento e na coloração vermelha dos frutos.

3. As telas antigranizo branca e preta reduzem a incidência de queimadura por sol, porém não têm efeito sobre a severidade de "russeting" e sobre o número de sementes por fruto.

\section{Agradecimentos}

Ao CNPq, pelo apoio financeiro.

\section{Referências}

ARAKAWA, O. Photoregulation of anthocyanin synthesis in apple fruit under UV-B and red light. Plant Cell Physiology, v.29, p.1385-1389, 1988.

AWAD, M.A.; WAGENMAKERS, P.S.; JAGER, A. de. Effects of light on flavonoid and chlorogenic acid levels in the skin of 'Jonagold' apples. Scientia Horticulturae, v.88, p.289-298, 2001.

CHEN, K.; HU, G.Q.; LENZ, F. Training and shading effects on vegetative and reproductive growth and fruit quality of apple. Gartenbauwissenschaft, v.62, p.207-213, 1997.

DOWNS, R.J.; SIEGELMAN, H.W.; BUTLER, W.L.; HENDRICKS, S.B. Photoreceptive pigments for anthocyanin synthesis in apple skin. Nature, v.205, p.909-910, 1965.

DUSSI, M.C.; GIARDINA, G.; SOSA, D.; GONZALEZJUNYENT, R.; ZECCA, A.; REEB, P. Shade nets effect on canopy light distribution and quality of fruit and spur leaf on apple cv. Fuji. Spanish Journal of Agricultural Research, v.3, p.253260, 2005.

GARDNER, R.A.W.; FLETCHER, C.A. Hail protection systems for deciduous fruit trees. Deciduous Fruit Grower, v.40, p.206$212,1990$.

KREUZ, C.L.; PETRI, J.L.; SUZUKI, A. Viabilidade econômica do uso de tela antigranizo em pomares de pêra-japonesa. Revista Brasileira de Fruticultura, v.24, p.416-419, 2002.
LAMBERS, H.; CHAPIN, F.S.; PONS, T.L. Plant physiological ecology. New York: Springer-Verlag, 1998. 540p.

LEITE, G.B.; PETRI, J.L.; MONDARDO, M. Efeito da tela antigranizo em algumas características dos frutos de macieira. Revista Brasileira de Fruticultura, v.24, p.714-716, 2002.

MARCELINO, I.P.V.O.; MENDONÇA, M.; RUDORFF, F.M. Ocorrência de granizo no estado de Santa Catarina. In: SIMPÓSIO BRASILEIRO DE DESASTRES NATURAIS, 1., 2004, Florianópolis. Anais. Florianópolis: GEDN/UFSC, 2004 p. 795805. 1 CD-ROM.

MARTINEZ, J.F.; MILLAN, M.; GARCIA, N.; LOPEZ, F.V.; DELGADO, A.; GARCIA, R.; RODRIGUEZ, J.A.L.; REYES, E.; MARTIN, J.A.R.; GOMEZ, A.C. Compositional heterogeneity of hailstones: atmospheric conditions and possible environmental implications. Ambio, v.30, p.452-454, 2001.

MIDDLETON, S.; McWATERS, A. Hail netting of apple orchards: Australian experience. Compact Fruit Tree, v.35, p.51-55, 2002.

PASSOS, L.P. Métodos analíticos e laboratoriais em fisiologia vegetal. Coronel Pacheco: Embrapa-CNPGL, 1996. 223p.

POLDERVAART, G. Hail nets: reliable method of hail protection. Fruitteelt Den Haag, v.96, p.12-13, 2006.

REAY, P.F.; LANCASTER, J.E. Accumulation of anthocyanins and quercetin glycosides in 'Gala' and 'Royal Gala' apple fruit skin with UV-B-visible irradiation: modifying effects of fruit maturity, fruit side, and temperature. Scientia Horticulturae, v.90, p.57-68, 2001.

STAMPAR, F.; VEBERIC, R.; ZADRAVEC, P.; HUDINA, M.; USENIK, V.; SOLAR, A.; OSTERC, G. Yield and fruit quality of apples cv. Jonagold under hail protection nets. Gartenbauwissenschaft, v.67, p.205-210, 2002.

TASSARA, M.A.; BATTAGLIA, M. Ensayo de una red plastica antigranizo en manzanos en el Alto Valle de Rio Negro. Rivista di Agricoltura Subtropicale e Tropicale, v.86, p.375-384, 1992.

WARNIER, O. The influence of an anti-hail net on the quality of fruits and their production. Fruit Belge, v.72, p.86-93, 2004.

WIDMER, A. Light intensity and fruit quality under hail protection nets. Acta Horticulturae, n.557, p.421-426, 2001.

YURI, H.M. Gestão de risco de granizo pelo seguro e outras alternativas: estudo de caso em pomares de maçã de Santa Catarina. 2003. 145p. Dissertação (Mestrado) - Universidade de São Paulo, Piracicaba.

Recebido em 28 de março de 2007 e aprovado em 19 de junho de 2007 